\title{
Discussion on Comprehensive Improvement of Xinzui River Section in Hanshou County
}

\author{
Liu Aiguo ${ }^{1,3}$, Peng Jiuhua ${ }^{1}$, Cao Lijun ${ }^{1}$, Wu Feng ${ }^{1}$, Zhou Shangong ${ }^{2}$ \\ ${ }^{1}$ Hanshou County Water Resources Bureau, Hunan Province, Changde, China \\ ${ }^{2}$ Hanshou County Minnan Water Resources Management Committee, Changde, China \\ ${ }^{3}$ Hunan Open Source Hydropower Construction Engineering Co., Ltd., Changde, China
}

Email address:

Liuaiguo003@126.com (Liu Aiguo)

\section{To cite this article:}

Liu Aiguo, Peng Jiuhua, Cao Lijun, Wu Feng, Zhou Shangong. Discussion on Comprehensive Improvement of Xinzui River Section in Hanshou County. American Journal of Water Science and Engineering. Vol. 5, No. 1, 2019, pp. 1-8. doi: 10.11648/j.ajwse.20190501.11

Received: November 9, 2018; Accepted: December 4, 2018; Published: January 29, 2019

\begin{abstract}
The river channel of the Xinyizui to the car brain flood control embankment in the south of the Hanshou Lake in the Dongting Lake area is a typical bifurcation channel. Big After the first and second phases of the Dongting Lake area, the embankment was affected by the quality conditions of the embankment and the river regime. There were still dangers such as bank collapse, leakage and piping during the flood season. Analyzed the causes of the dangerous situation, and proposed comprehensive measures to strengthen the river control, static water filling and other measures. After the treatment, there was no danger in the levee of the river section in the flood in 2017, and the treatment effect was remarkable. Governance measures have certain reference significance for river regulation, embankment control and flood control in Dongting Lake area.
\end{abstract}

Keywords: Dongting Lake District, Flood Control Embankment, Still Water Filling Comprehensive Remediation

\section{Overview}

\subsection{Status of the River Section}

Weinan Temple is located in Hanshou County, Hunan Province, west of Dongting Lake, on the south bank of Lishuiwei. It is one of the 11 key gongs in the Dongting Lake area and an important commodity grain base in Changde City. The social and economic status is very important. The total area of total protection is $464 \mathrm{~km}^{2}$, with a total population of 245,000 . Lishui from the emerging mouth into the territory to the Jiangjiazui water gate, the Linhong levee is $52.65 \mathrm{~km}$ long. The $10 \mathrm{~km}$ outer river section of the upstream emerging mouth to the car brain flood control embankment (station number $0+000$ to $10+000$ ) is a typical branching flood road, which is divided into north, middle and south. Beibei passes through Niubi Beach and enters Anpeng Port. The length of the ramp is $13 \mathrm{~km}$. It is a navigational passage in history. The Jinshi River in Zhongli is a straight river channel for artificial cutting in 1970. It is exported to Anpeng Port by Da Panzhou and Xiao Pan Chau. It is $6.98 \mathrm{~km}$ long; Nanxun is about $16 \mathrm{~km}$ long. After the flood, it flows into Beibei [1] opposite to Niubitan Town; the flood river above Xinxingzui is $1.1 \mathrm{~km}$ wide, and the dry river is about $450 \mathrm{~m}$ wide. When the water is in the river, it is about 300 to $900 \mathrm{~m}$ wide. The water goes to the north, the middle and the south, and there is no floodplain. When the flood reaches the lake, the floodplain, the floodplain and the small pan-continent, the water surface is $6.5 \mathrm{~km}$ (see figure 1 for river regime). The highest flood level of the river section (Juhu Lake faint station on July 18, 1996) was $40.93 \mathrm{~m}$ and the flow rate was $29100 \mathrm{~m}^{3} / \mathrm{s}$ (Taoyuan Station).

\subsection{Status of the Levee}

Since the completion of the embankment in 1949, the state and local governments have invested a large amount of manpower and financial resources in the construction of the embankment, especially through the comprehensive treatment of the first phase of the flood control embankment during the 14 years from 1986 to 2010. In the second phase of reinforcement, the embankment is fixed and the high-spray grouting is carried out on the emerging mouth to the car brain flood control embankment; the dredger in the inner slope pit and low-lying area is dredged and immersed; the pressure inside the inner leg is sealed within $300 \mathrm{~m}$. well. 
The elevation of the embankment is 41.7 to $41.6 \mathrm{~m}$, the top surface of the embankment is $8 \mathrm{~m}$ wide, the slope of the waterfront is $1 . .3$, the ratio of the backwater slope is $1 . .2 .5$, and the height of the embankment is $10.4 \mathrm{~m}$.

Although after many years of treatment, there are still many hidden dangers in the flood control embankment of Weinan, especially the emerging mouth to the car brain flood control embankment in the flood season, the danger is numerous. First, the embankment collapsed during the flood period, and the water retreats and de-slopes; secondly, there are different degrees of leakage in the embankment; thirdly, there are piping and piping groups in the high flood period except for the filling of the embankment and the low-lying unfilled areas. There is a tendency for the local area to flow to the rear farmland. In the local area, there are folk songs that are "new year, old age, more repaired and more dangerous". Every year in the flood season, local governments have to be ahead of schedule, and "heavy soldiers" guard them. Therefore, the new mouth to the car brain flood control embankment in the south of Fujian Province is still the key and difficult point of the Hanshou County government's current flood control.

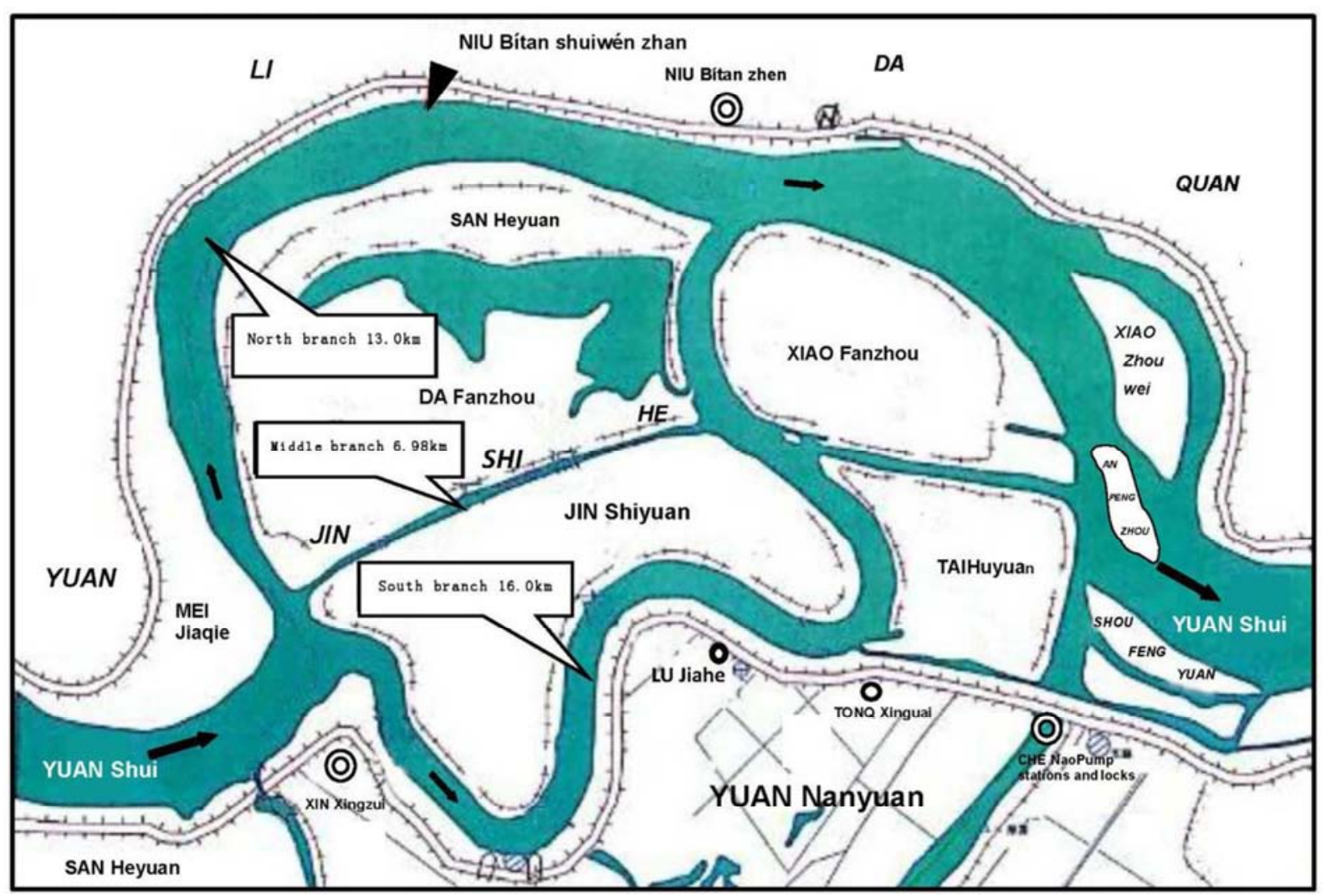

Figure 1. Yuan Nanyuan XIN Xingzui to CHE Nao River regime diagram of branched channel in river reach.

\section{Dangerous Causes}

\subsection{River Change}

During the high flood period of the emerging mouth to the car brain flood control embankment, the river surface became the lake surface, the surface width was 7.2 times that of the middle water period, the water flow was dispersed, the flow rate was slowed down, and the sedimentation was serious, which led to the development of the willows in the Jinshi Weizhou beach. Development in turn aggravated sedimentation. At present, the Jinshi Weizhou beach was silted from $30.3 \mathrm{~m}$ to $31.06 \mathrm{~m}$ at the time of demolition, and the area of Tamarix chinensis was increased from zero area at the time of deforestation to $11.73 \mathrm{~km}^{2}$.

Although the Gaohong Lake in this section is wide, due to the shallowness of the Zhongmu River, and the accumulation of the Jinshi River in the middle of the lake, the silt will develop and form a water-blocking river. In the middle of this section, there is the Niubi Beach hydrological station. During the flood in 1995, the ratio of Xinzui to Niu Naotan was only $0.037 \%$, which was smaller than the upstream section of Qiujia faint to the emerging mouth of $0.083 \%$ and the downstream section of Niu Naotan to Zhouwen Temple. Much more [2]. The water level in the bayonet section is high, and the water surface ratio above the bayonet is slower. The rivers in the north and south of this section are curved, and the embankments on both sides of the river are rushing, especially the Nanxun River, which is long and narrow, and is deep and sloping, together with the top of the Meijiao shoal in the Xinmei Mouth, and the water in the middle of the Jinshi The flood level of the flooding has risen sharply. From $8 \mathrm{~h}$ to $24 \mathrm{~h}$ on June 24th, 2017, the water level of the Xinmou Nanpan Panhu Lake station rose from $34.98 \mathrm{~m}$ to $37.5 \mathrm{~m}$ and reached the warning water level (the warning water level of the station is $37.5 \mathrm{~m}$, the water level is 
guaranteed to be $40.0 \mathrm{~m})$., $16 \mathrm{~h}$ rose $2.52 \mathrm{~m}$, rising $0.16 \mathrm{~m}$ per hour. According to the "three defenses" water level in the 1990 s, the water level of the station was controlled to a dangerous water level of $2.0 \mathrm{~m}$, which is the daily "three-proof" water level. Therefore, the emerging mouth levee flood control must now be ahead of the "two defenses" preparation, otherwise, it will be impossible to prevent.

The flood level rose sharply, which increased the flood flow and erosion flow rate of Nanxun. Under the action of the circular circulation, the bank slope is subjected to rushing. Under the scouring of the water flow, the levee floods and collapses, and the water falls off the slope. In 2006, the outer landslide of Panhu dike section (station 2+700) was $200 \mathrm{~m}$ long, and the maximum offset was $1.3 \mathrm{~m}$. The outer landslide of the concentric bank (station 7+700) was $100 \mathrm{~m}$ long and the maximum offset was $0.5 \mathrm{~m}$. The outer landslide of the lake dim section (station 2+400) is $150 \mathrm{~m}$ long, the maximum offset is $1.0 \mathrm{~m}$, the crack width is 10 to $30 \mathrm{~cm}$, and the concentric kelide section (station number $7+200$ ) is $100 \mathrm{~m}$ long and the maximum offset is $0.5 \mathrm{~m}$. The crack is 10 to 15 $\mathrm{cm}$ wide.

\subsection{Levee Problem}

According to the typical section geological survey, the flood control embankment is the Quaternary Holocene artificial accumulation $\left(\mathrm{Q}^{\mathrm{s}}\right)$ with an elevation of more than $31.66 \mathrm{~m}$ : most of them are silty clay, taupe, plastic to hard plastic, loose structure, local overhead phenomenon, mainly It is a flood control embankment. The elevation of $31.66 \mathrm{~m}$ is the Quaternary Holocene Chonghu accumulation $\left(\mathrm{Q} 4^{\mathrm{a}+\mathrm{l}}\right)$ : the upper elevation 31.66 to $28.61 \mathrm{~m}$ is loam; the middle elevation 28.61 to $16.96 \mathrm{~m}$ is silty silty clay; the elevation $16.96 \mathrm{~m}$ to below is gravel [3].

The layered concealed gravel under the embankment is a strong permeable layer. The riverbed is washed by the water flow over the years. The river bottom elevation is 4.86 (station number $0+500$ ) to $28.46 \mathrm{~m}$, the river bottom average elevation is $16.66 \mathrm{~m}$, and the emerging mouth inlet is the lowest. The exposed thickness of the riverbed gravel layer is $12.1 \mathrm{~m}, 240 \mathrm{~m}$ away from the center of the levee. The outer river gravel layer is bare, and there is no anti-seepage cover clay layer. This is the most important reason for the new-mouth-to-vehicle flood control embankment section, "yearly repair, annual insurance, and more repair and more dangerous". In addition, the interior of the embankment is low, and the ground elevation is 30 to $33 \mathrm{~m}$. The cover layer is thin and only 2 to $3 \mathrm{~m}$ thick. During the flood season, the river floods communicate with the groundwater in the levee foundation. When the water level is high, the osmosis slope becomes steeper. When the osmotic slope is greater than the allowable osmosis slope of the weak aquifer in the surface layer, the osmotic damage occurs at the foot of the levee and its vicinity.. The fine sand particles in the lower layer are taken out to cause sand and water, also known as piping. Light leaks, a small amount of sand, and heavy hollowing out the foundation, causing the ground and the embankment to collapse, endangering the flood control safety of the flood.
The basic characteristics of the dangerous situation over the years are: the water level of the river reaches or exceeds the warning water level, and within $400 \mathrm{~m}$ of the foot of the levee, there is a tube surge in the low-lying field, the grooved fish pond, the home-based water well and the pothole cemetery [4]. The initial sand disc diameter is 0.1 to $0.4 \mathrm{~m}$. Later, the small eyes are big eyes, the range of eye groups is continuously expanding, and the range can reach thousands of square meters. The large area of the eyes is filled with water and sand, and the whole piping area is like boiling porridge, splashing water, The mud is sprayed with sand and the height of the gushing water column can reach $0.8 \mathrm{~m}$. The nearest foot is $10 \mathrm{~m}$ away from the embankment (at 17:00 on July 1 , 2017, the water level is $39.23 \mathrm{~m}$, the car brain levee section $<$ station number $9+300>$ two slopes on the inner slope); The farthest distance from the embankment is $380 \mathrm{~m}$ (at 6 o'clock on the afternoon of July 17, 2014, the water level is $39.85 \mathrm{~m}$. The Qixin Formation of the Lujiahe Village of Xinxing Township is $5+900$, and there is a tube group in the rice field, of which the main trachoma 5 places, the maximum diameter is $1.5 \mathrm{~m}$, the highest water column is $0.8 \mathrm{~m}$, the trachoma group is about $1500 \mathrm{~m}^{2}$, and the black sand is nearly $150 \mathrm{~m}^{3}$. The local ground soil is softened and people can't stand).

It is worth mentioning that the dike section used high-spray grouting due to leakage of the embankment and the drowning of the sand, that is, vertical anti-seepage technology, but the impervious seepage is not ideal. The reason is that the levee stands tall, from $41.7 \mathrm{~m}$ at the top of the levee to $16.96 \mathrm{~m}$ at the top of the gravel layer, with a thickness of $24.74 \mathrm{~m}$. If the vertical anti-seepage of the gravel layer is considered to be $5 \mathrm{~m}$, the vertical anti-seepage thickness of the levee is $29.74 \mathrm{~m}$. At that time, the construction equipment and technology had reached the anti-seepage requirement. It can only be a suspended anti-seepage wall. The anti-seepage effect of the suspended anti-seepage wall is very poor. Therefore, there is still leakage and drowning in the embankment.

Furthermore, the vertical anti-seepage is only suitable for the embankment foundation where the permeable layer is thinner and the dike section is not long (such as a reservoir). At this time, it can be made into a closed vertical anti-seepage, which basically cuts off the rivers, rivers and lakes during the flood period. The recharge of groundwater by the reservoir water, the leakage of the embankment and the piping can be completely cured [5]. However, it must be implemented after the survey data is sufficient and through detailed calculation of seepage calculation and technical and economic comparison, so as to avoid waste.

In view of the length of the emerging mouth to the car brain flood control embankment, the standing height and the water barrier are very deep, it is not suitable to use the vertical anti-seepage of the high-spray grouting of the embankment. In addition to the high cost of vertical anti-seepage of high-spray grouting and the difficulty of construction, it is more important that closed vertical anti-seepage cuts off the way of replenishing the external 
river water and groundwater, which may have certain impact on the ecological environment.

\subsection{Human Problems}

The flood control embankment of Weinanyu was built in the 1950s and 1980s by the people of Hanshou, building the Dongting Lake area, blocking the flow of the river, renovating the flood road, strengthening the embankment, fighting the land, and lifting the shoulders. Due to artificial picking, it was necessary to take the soil near the embankment and the river channel along the embankment. In this way, it is inevitable that the surface soil anti-seepage cover of the river bed outside the levee will not be damaged.

After the 1990s, with the development of science and technology, the flood control embankment used mechanical heightening and thickening and dredgers to carry out the flooding and immersion of the low-pitched shovel in the levee. Because the dredger at the time was not equipped with advanced equipment, the transportation distance was limited. Therefore, no matter whether the mechanical borrowing and dredging of the dredger can not solve the problem of long-distance soil borrowing, the rogue will still take the residual soil of the original artificial soil field. On the contrary, it will accelerate the destruction of the surface soil anti-seepage cover.

Because there was no standard sand mining area for river sand mining in the last century, the chaos in the river channel was repeatedly prohibited. In particular, the emerging mouth of the mouth is especially prominent. The deep excavation of the gravel destroyed the anti-seepage cover, causing the riverbed to be severely cut, the deep trough forced the shore, the rapids cut the foot, endangering the levee, and more importantly, opening the "gate" of Nanxun, or excavating the "iron gate", plus Big floods [6]. The flow that should have been split into the middle of the road was introduced to Nanxun. It can be said that this is one of the reasons for the steep rise of the water level in the flood season of the South Lake.

Within 300 meters of the foot of the levee, there are still farmers hiding the pressure wells, the drought-resistant wells in the group and the centralized water supply wells in the village. These wells have turned over the sand in the flood season in 2017.

\section{Comprehensive Remediation}

In view of the problems of the dikes and rivers in the river section, it is necessary to implement "enhance the lieutenant, fill the south, shrink the north, gradually abolish the north and south, and achieve the three-in-one; centralized water supply, electric power irrigation; protection of the embankment, Comprehensive management plan for regulating sand mining.

\subsection{Strengthening the Lieutenant Rooting the Flood}

The Jinshiyu section of the Zhongmu is a typical goose-shaped ramp connected to the "cs" river channel. Its branching coefficient is 2.36 , the ramping rate is 5.72 , the length-to-width ratio of the branching section is 0.93 , and the aspect ratio of Jiangxinzhou is $0.89^{[2]}$. In order to solve the situation of the water flow in the Jinshiyu River section and the dikes on both sides of the river, after the 1969 winter waste gold stone, Han Shou lifted the power of the county, and fought in the three winters in 1970, 1979 and 1980 respectively. Digging, the tiger's mouth is broken, the small Panzhou excavation traverses the Nanxun Jinshi River (known as artificial river), the river bottom width is 120 (import) to $60 \mathrm{~m}$, the bottom elevation is 27.7 to $26.7 \mathrm{~m}$, and the total length is $6.98 \mathrm{~km}$ (including Dapanzhou section is $3.9 \mathrm{~km}$, Nanxie Laohe trough is $0.78 \mathrm{~km}$, Xiaopanzhou section is $2.3 \mathrm{~km}$ ), and Sancha is in Anpengzhou Confluence. The Sanyuzhong River has the smoothest flow in the Jinshi River. Because of the small cross-section of the artificial excavation at that time, plus the river bed elevation of 28 to $20 \mathrm{~m}$ is $8 \mathrm{~m}$ thick clay layer. Therefore, the Xinkai River channel could not be opened, resulting in the Zhongshi Jinshi River not becoming the mainstream. The Xinhe River channel was in a state of erosion and siltation, and the average thickness of the bank on the banks of the river channel since the demolition in 25 years (1970-1995) $0.80 \mathrm{~m}$, causing the reeds to grow, causing the water flow disorder in the Jinshitun section, and the situation of the top-rise embankment can not be resolved.

In order to make the water flow of the Zhongshi Jinshi River smooth, take advantage of the situation, avoid the flooding of the south and the north and the scouring of the dike, get rid of the cornering danger, make the middle dry water return to the middle, beam the water to attack the sand, improve the river flooding conditions, and extend The life of the river channel will alleviate the serious accumulation of the Jinshi Meizhou beach, and gradually achieve the purpose of abolishing the North and South, and Sanshui. The dredging will be deepened and widened by the artificial river of Zhongshi Jinshiyu, and the floods will be strengthened and the floods will be cured.

\subsubsection{Cut off the Meijia Cut Beach}

Excavation of the Mei family cut into the river caused the flow of water to change the Bund, so that the mainstream north moved straight into the middle. The excavation area is basically arched, with a chord length of $1.5 \mathrm{~km}$. The opposite of the emerging old steamship wharf is the apex of the arc. It is digged $450 \mathrm{~m}$ horizontally from the ground elevation of $25.5 \mathrm{~m}$ to the Meijia cut, and the excavation area is about $550,000 \mathrm{~m}^{2}$. See Figure 2 .

\subsubsection{Dredging and Widening the Zhongshi Jinshi River}

The upstream reservoirs in the Qinshui River have been built with Fengshui and Wuqiangxi reservoirs with regulating functions. The flood discharge process is slowing down, and the northern slopes in the middle and dry seasons are still overcurrent. The construction method adopts "Beibei over circulation, Zhongyu dredging and widening, and Nanzhao hydrostatic filling". That is to say, the Beaver 3800 cutter suction dredger was used to continue to widen the depth of 
the excavation of the Zhongyu Jinshiheyuan River section, and the length of the dredging and remediation channel was $6.98 \mathrm{~km}$. The annual average annual flow rate of $2004 \mathrm{~m}^{3} / \mathrm{s}$ is used in the excavation of the Jinshi River in the excavation. The effect of the dredging is further considered to gradually increase the average flow rate or the flat beach flow during the flood season, so as to eventually replace the north and south. Diversion situation.

The river dredging width is determined by factors such as design flow, riverbed roughness and river relationship. According to the calculation formulas of hydraulics and river dynamics, the formula for calculating the B-value of the river width is:

$$
\mathrm{B}=\left(\frac{\mathrm{nQE}^{5 / 3}}{\mathrm{~J}^{1 / 2}}\right)^{6 / 11}
$$

In the formula: $\mathrm{Q}$-Design flow $\left(\mathrm{m}^{3} / \mathrm{s}\right)$;

$\mathrm{n}$-Channel roughness;

E - River phase coefficient;

$\mathrm{J}$-Water surface ratio;

B - Channel dredging width (m).

After calculation, it is proposed that the dredging width of the river channel is 690 (import) to $400 \mathrm{~m}$, and the river bottom elevation is 28.98 to $27.65 \mathrm{~m}$. See Figure 2 .

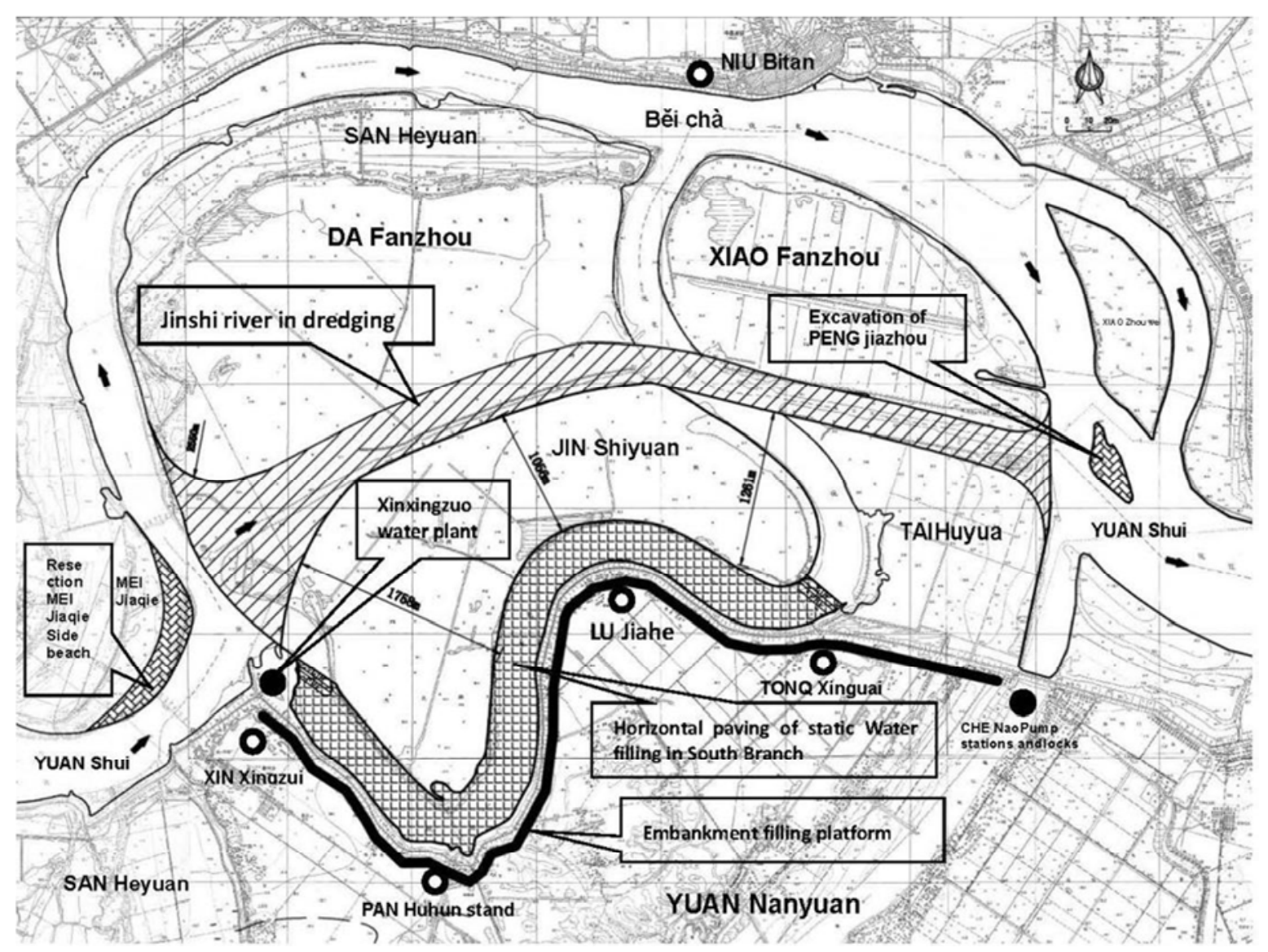

Figure 2. YUAN Nanyuan XIN xingzui to CHE Nao Schematic Diagram of Comprehensive Regulation arrangement of river reach.

By re-drilling the depth of the original scorpion again, it can be truly realized: First, it is guided by the situation to ensure smooth flow of the river, and gradually abolish the north and south, and achieve the "three branches to one"; the second is to get rid of the corner danger and river The embankment is flushed by $14.37 \mathrm{~km}$; the third is to shorten the Beibei process (ship) by $6.02 \mathrm{~km}$, the Nanxun process (ship) by $9.02 \mathrm{~km}$, and the smooth flow; and the fourth is to reduce the emerging mouth high flood level by $0.2 \mathrm{~m}$, which is most beneficial for flood control;

\subsubsection{Excavation of an Pengzhou}

An Pengzhou is located in the east of Xiao Panzhou, the heart of the Lishui River, lying across the water outlet of the
Zhongshi Jinshi River, blocking the floods in the middle. The continent is in the shape of a gourd with an area of about $55,000 \mathrm{~m}^{2}$ and a ground elevation of $33.5 \mathrm{~m}$. Digging to the bottom of the riverbed $27.65 \mathrm{~m}$, is conducive to flooding. See Figure 2.

\subsection{Filling the Nanxun Anti-Seepage Cover}

The dredging earthwork of the Zhongshi Jinshi River is mainly composed of sandy clay, and the silty clay accounts for about $15 \%$. After calculation, the dredging earthwork is 16.79 million $\mathrm{m}^{3}$ and the sludge is $530,000 \mathrm{~m}^{3}$. With the development of science and technology, at present, Beaver 3800 cutter suction dredgers can reach a distance of $3.5 \mathrm{~km}$ and a height of $5 \mathrm{~m}$. The maximum blowing distance of the 
dredging to the south is $16100 \mathrm{~m}$. It fully meets the filling distance and can play the role of one stone and three birds.

\subsubsection{Still Water Filling}

The riverbed anti-seepage cover has been seriously damaged in the Xinyi mouth to Tongxinjiao (station 0+000 to $8+000)$ section. In order to restore the original anti-seepage cover layer, the middle layer of dredged clay in the dry season is used to blow to the Nantun section. (Blocking the dam downstream of the river filling section, try to reach the still water in the landfill to prevent soil erosion). Then use water to dig the machine.

According to the "Watergate Design Code" (SL265-2001). The thickness of the cover is calculated as follows:

$$
\delta=\frac{\Delta \mathrm{H}}{[\mathrm{J}]}
$$

In the formula: $\delta$ - Cover thickness, $(\mathrm{m})$;

$\Delta \mathrm{H}-$ Cover the top and bottom of the head, (m), $\Delta \mathrm{H}=22.5$;

$[\mathrm{J}]$ - The allowable slope of the material, clay and loam are generally 4 to 6 , $[\mathrm{J}]=5$.

The designed flood level of the dike is $39.16 \mathrm{~m}$, the elevation of the bottom of the river bed is 4.86 to $28.46 \mathrm{~m}$, the average elevation of the bottom of the river bed is $16.66 \mathrm{~m}$, and the head difference of the top and bottom of the pavement is $22.5 \mathrm{~m}$. After calculation, the minimum thickness of the horizontal filling of the river is calculated. $4.5 \mathrm{~m}$, it is determined that the horizontal filling of the filling is $5 \mathrm{~m}$.

The anti-seepage cover is filled through the Nanzhao hydrostatic water, which not only stabilizes the outer feet of the levee, increases the seepage diameter of the embankment, reduces the groundwater head difference, radically cures the "disease" piping and piping groups, and avoids the high-spray grouting cutting groundwater recharge. The drawbacks of the channel. In 2016, the first stage of the Nanxun Xinzui to Tongxinjiao (station $3+500$ to $6+500$ ) will be filled with static water. After the trial of the new mouth high flood level of $39.85 \mathrm{~m}$ in 2017 , the embankment during the flood control period There was no danger in the area, and the local people responded well and achieved remarkable results. They strongly demanded that they continue to fill out. The unfilled river section is still in danger.

What is more prominent is that after the Nanxun fills the anti-seepage cover, there are attractive business opportunities and good development prospects. In view of the abundant sand source at the bottom of Zhongyuzhou Beach, through standardization and designated mining, the sand is blown into the Nanxun anti-seepage cover to create the Huangshui River Basin-Hanshou Xinxingou River Natural Sand Beach Amusement Park and Shallow Water Beach Baths.

\subsubsection{Pressure Dipping}

The first and second phases of the treatment are mainly for the flooding levee section of the emerging mouth to concentric turn (station $0+000$ to $8+000$ ) over the years. The blowing distance is 60 to $100 \mathrm{~m}$ and the elevation is 32 to $34 \mathrm{~m}$ [7]. At that time, the main reason was that the blowing distance and soil source problems could not be implemented in the whole section of the low-lying area. In addition, the concentric turn to the car brain (station number $8+000$ to $10+000)$ flood control embankment in the dry season, the outer river became a beach, the dredger could not be filled, and the anti-seepage cover inside and outside the levee was thin, so that it was flood season. More dangerous locations.

In combination with the widening of the dredging in the middle, the dredging earthwork was blown into the foot of the emerging mouth to the car brain flood control embankment, the uniform filling width was $100 \mathrm{~m}$, the filling height was $35.0 \mathrm{~m}$, and the floodplain secondary platform was used for filling. In this way, both the levee is strengthened and the channel volume is increased. At the same time, the $100 \mathrm{~m}$ wide platform can be planned to build houses, plant grass grazing (local sheep farming custom), to create beautiful countryside, along the river scenery belt. See Figure 2.

\subsection{Centralized Water Supply}

The emerging mouth to the car brain flood control embankment has dense housing. In the past, every household had pressure wells, and each group had irrigation wells. With the annual flood season, the dangers of wells and irrigation wells continue to emerge. On the one hand, the water conservancy department requires that the foot of the levee be blocked within $300 \mathrm{~m}$ and the well should be blocked; on the other hand, it is supported to build a centralized underground water supply plant and a new small irrigation and drainage station by the village. However, due to the small scale of the water plant, the small amount of water in the household, and the high price of water; the high cost of irrigation and drainage in small-scale irrigation and drainage stations, at present, there are still farmers who drill wells and groups to keep irrigation wells; and the centralized water supply stations in the village are not properly located, away from the embankment. Very close, such as Lujiahe Village centralized water supply station. In the unfilled areas, these wells and stations have been in danger during the 2017 flood season.

In view of the above problems, it is recommended to build a new mouth surface water plant and plan a new mouth irrigation area for the car brain pump station.

\subsubsection{Xinxingouou Surface Water Plant}

A new centralized water supply surface water plant with a certain scale will be built along the Xinshui River to ensure the local water supply; reduce the cost of water supply; replace the traditional groundwater with surface water to ensure the quality of water supply.

\subsubsection{Plan the Irrigation and Drainage Area of the Car Brain Pump Station}

With the realization of the target of Nanxun filling and filling, Nanxun will change from a river to a beach, and the water conservancy buildings such as the current entrance, the 
sluice gate, the faint culvert, and the electric platoon will be lost. The farmland irrigation and drainage area in the village must be re-planned.

In 2013, the water conservancy department built a new medium-sized pumping station in the emerging car brain. Using the car brain pumping station, combined with the river remediation, the new driving brain pumping station west drainage irrigation channel, the establishment of the car brain pumping station in the west of the new mouth irrigation area.
According to the 2011 "Hangshou County River and Lake Connection Project Planning Report", a large-scale inlet, outlet and ship lock should be built next to the Chepo Pumping Station [8]. See Figure 3. In this way, self-irrigation and electric irrigation can be realized by newly opening the west drainage channel. The water conservancy department should start reporting to the higher authorities in advance so that the project can be established as soon as possible.

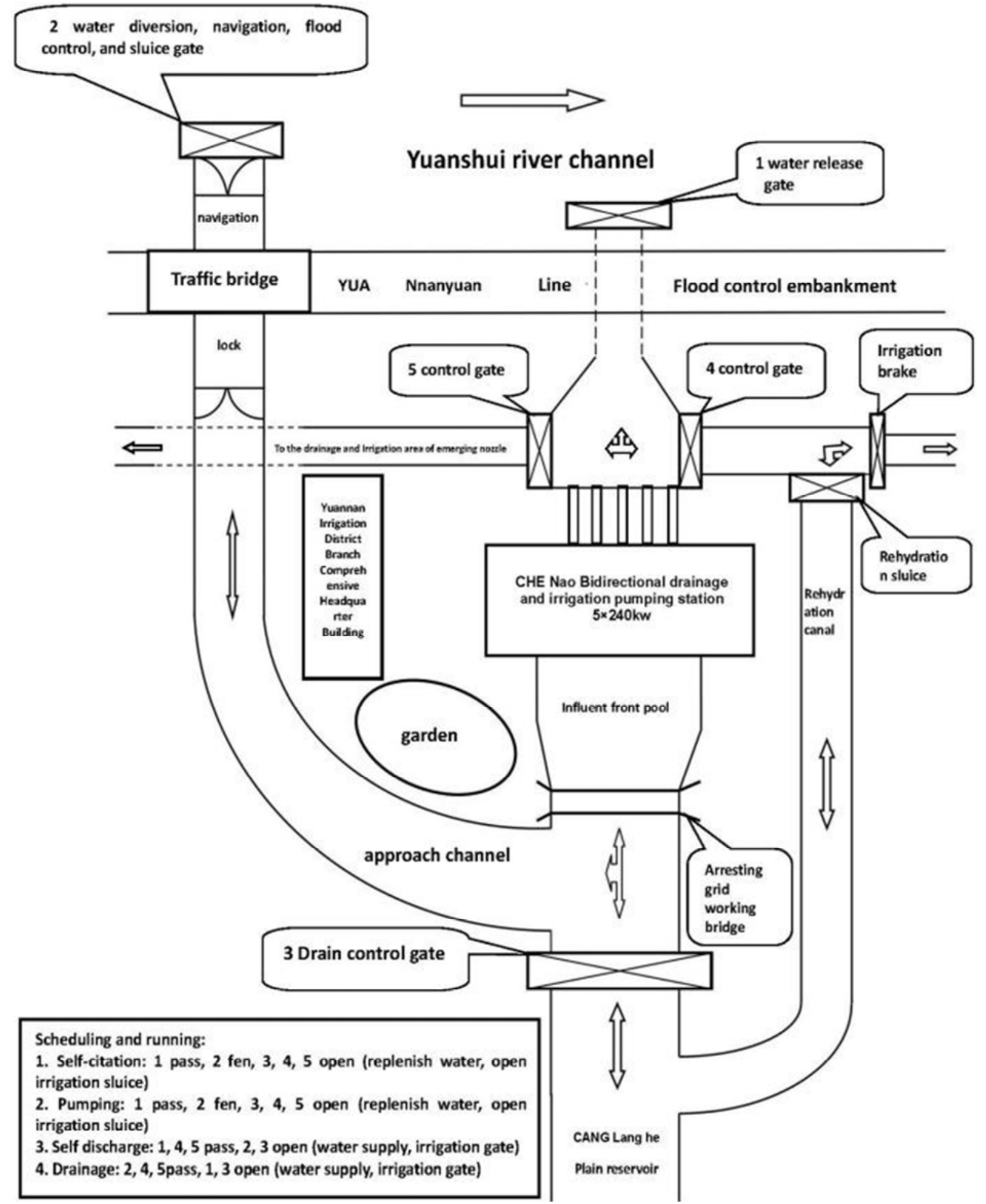

Figure 3. CANG langhe PING yuan SUHI ku CHE Nao Two-way drainage and irrigation pumping station building layout drawing. 


\subsection{Protecting the Embankment}

Riverbed sandstone is the material foundation for river stability and water-sand balance. The river sand available for mining is a valuable resource that is difficult to regenerate. Unrestricted, predatory mining of river sand will destroy the river's river regime and undermine the balance of the river bed [9]. Therefore, the formulation of river sand mining planning is the basic work for rational development and utilization of sandstone resources. It is necessary to guide the formulation of the Plan with a scientific outlook on development. In terms of the emerging to the Chena River section, the north and south shoals should be designated as forbidden mining areas, and the central and eastern beaches are classified as mining areas. After the implementation of the sand mining project, the diversion ratio of the Zhongshi Jinshi River shows a significant increase trend. On the contrary, the diversion ratio of the north and south dips is reduced, which is conducive to the goal of "three-in-one" in the dredging planning [10]. This not only exerts resource efficiency, but also expands the river channel volume, does not affect the safe flooding of the river channel, and clears obstacles for the river channel.

\section{Conclusion}

The Xinyizui to Chenahe section of Weinan is a systematic project for river regulation, dike management and flood control. It is also a project that is interrelated and has a combination of short-term and long-term projects. It is also a provincial macro. The project has a development prospect, such as the effect of the river, the embankment, and the flooding.

The project was implemented in 2016 and showed great results at the beginning of 2017. It is believed that under the leadership of the local government, the water conservancy department will increase investment and speed up governance, and create a typical example of water control in the Dongting Lake area with great peace, harmony of people and water.

\section{References}

[1] Lü Jingjun, Fan Luzhen et al. Analysis of the influence of river sand mining on the river regime of the Tenghe River [J]. Hunan Water Resources and Hydropower, 2016 (4): 54-55.

[2] Hunan Provincial Institute of Water Resources and Hydropower Survey and Design. Implementation plan for the comprehensive remediation project of dredging and levee reinforcement of Xinxingzui River in Hannan County, Hanshou County, Hunan Province [R].1996.

[3] Hunan Nuclear Industry Geotechnical Investigation and Design Institute. Engineering geological survey report of preliminary design stage of the flooding and dredging emergency rescue project in Lushui emerging Lujiahe dike section of Hanshui County, Hunan Province [R].2014.

[4] Zhang Wenhui. Study on construction technology of embankment filling ponds under pressure and seepage [J]. People's Yangtze River, 2009, (6): 25-41.

[5] Liu Qinghua. The prevention and cure methods of seepage prevention and reinforcement of reservoir dikes and dams are analyzed [J]. Technology and Life, 2010, (12): 117.

[6] Chen Xiaotao. Cause Analysis and treatment measures of landslide in Beijiang Embankment $[\mathrm{J}]$. Guangdong Water Conservancy and Hydropower, 2005, (6): 1-2.

[7] Chen Daizhen. A brief view on the treatment of the Shaji embankment in Wulin Temple, southern Fujian [J]. The Yangtze River, 1996 (12): 39-40.

[8] Wang Shuai, Liu Aiguo, Hu Jiaxing. An Analysis of the Water Conservancy Planning and Management of the Neijiang River in the Dike: A Case Study of the Canglang River in Hanshou County, Hunan Province [J]. Hunan Water Resources and Hydropower, 2014 (1): 32-34.

[9] Zhu Sufen, Chen Jing, Zhang Zhiyong. Present situation and Countermeasures of Sand Mining in the River course of the Yanhe River Basin in Anyang City [J]. Henan Water Conservancy and Water diversion from South to North, 2010, (11): 49-51.

[10] Nanjing Institute of Hydraulic Research. Research report on two-dimensional flow mathematical model of Jinshayu mining sand section of Lishuiweijing [R]. 2016.

\section{Biography}

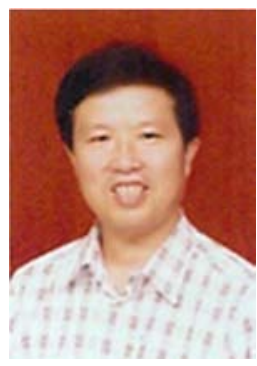

Liu Aiguo: High engineering. Expert team leader. Be engaged in water conservancy. Published 26 international, national, provincial papers, two monographs. Won the International Agricultural Fair bronze medal award, provincial science and technology fourth prize, hall science and technology first time. The province comments on "excellent young science and technology workers". The provincial government set up the first class of credit for flood control and disaster relief. The county party committee is engaged as an expert service center consultant. 